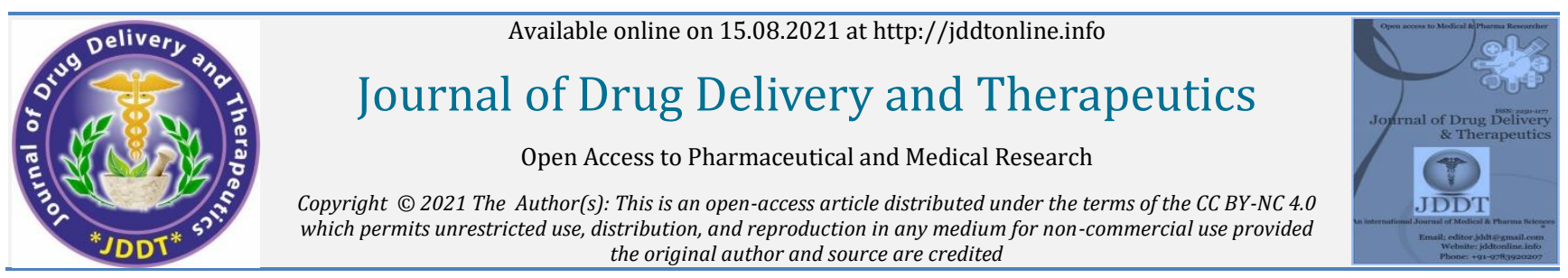

Open Access Full Text Article the original author and source are credited

\title{
Recent and Relevant Methodology in the Advancement of Solid Dispersion
}

\author{
Talla Shruti*, Wadher Kamlesh ${ }^{102}$, Umekar Milind ${ }^{2}$, Lohiya R.T.1* \\ ${ }^{1}$ Department of Pharmaceutical chemistry, Smt. Kishoritai Bhoyar College of Pharmacy, Kamptee Nagpur, Maharashtra, India 441002. \\ ${ }^{2}$ Department of Pharmaceutics, Smt. Kishoritai Bhoyar College of Pharmacy, Kamptee Nagpur, Maharashtra, India 441002
}

\section{Article Info:

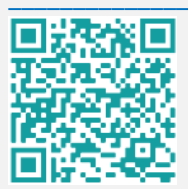 \\ Article History: \\ Received 21 June 2021 \\ Reviewed 25 July 2021 \\ Accepted 04 August 2021 \\ Published 15 August 2021}

Cite this article as:

Talla S, Wadher K, Umekar M, Lohiya RT, Recent and Relevant Methodology in the Advancement of Solid Dispersion, Journal of Drug Delivery and Therapeutics. 2021; 11(4-S):247-257

DOI: $h$ ttp://dx.doi.org/10.22270/jddt.v11i4-S.4963

*Address for Correspondence:

Mr. R.T. Lohiya, Smt. Kishoritai Bhoyar College of Pharmacy, Kamptee, Nagpur, Maharashtra, India 441002.

\section{Abstract}

Most of the promising drugs in development channels are poorly water-soluble drugs which limit formulation approaches, clinical application because of their low dissolution and bioavailability. And the major current challenges of the pharmaceutical industry are apropos strategies that improve the water solubility of drugs. Solid dispersion has been considered one of the major evolutions in overcoming these issues with several successfully marketed products. Though solid dispersion has been outlined as an efficient drug delivery system, the design of specific dosage forms for pharmaceutical therapy is necessary to improve the solubility and bioavailability of poorly water-soluble drugs. Solid dispersion can be prepared by several methods such as solvent evaporation, melting, and supercritical fluid technology. This review intends to provide an updated overview of the recent trends over the past few years in solid dispersion preparation techniques and polymer used. Along with the various pharmaceutical strategies and future visions for the solubilization of poorly water-soluble drugs

Keywords: Solid dispersion, Bioavailability, Solubility, Dissolution parameters, Polymeric carrier

\section{INTRODUCTION}

The most popular route of administration of the drug is oral route because it is simple and convenient way of administering drugs. Most of the newly developed drug shows poor solubility and absorption after oral administration despite their high permeability. ${ }^{1}$ During the development of new compounds the problem of great concern to scientist is solubility and dissolution. Recently various solubilization technologies have been developed to solve this challenge such as, solid dispersions, micronization, nanocrystalization, cyclodextrin complexes, micellar solubilization and liquisolid formulations and many more. ${ }^{2-}$ ${ }^{7}$ From these available technologies, solid dispersion (SD) method found promising results which enhances the solubility, dissolution and bioavailability. ${ }^{8}$ These can be defined as molecular mixtures of poorly water-soluble drugs in hydrophilic carriers. The dissolution characteristics enhancement of SDs are due to reduction in the drug particle size and the subsequent increase in the surface area, and improved wettability resulting from inmost contact with a hydrophilic carrier. ${ }^{9}$ Pharmaceutical dispersion systems such as, suspension system, colloidal system and solution system and amongst these the most popular systems are solid dispersion (SDs), lipid-based dispersion and liquisolid dispersion. ${ }^{10}$

For solid dispersions, polymeric carriers have used since long time, because of their ability to produce amorphous solid dispersions. They are classified as, natural based and synthetic polymers. Natural polymers mostly used are hydroxypropyl methylcellulose, ethylcellulose and hydroxypropylcellulose and cyclodextrins. Synthetic polymers include povidone, polyethyleneglycols and polymethacrylates. ${ }^{11-13}$ The present review article deals with all the important strategies of solid dispersion techniques and their applications in pharmaceutical dosage form development.

\section{STRATEGIES IN SOLID DISPERSION MANUFACTURING METHODS}

SD can be prepared by several methods such as solvent evaporation, melting, and supercritical fluid (SCF) technology as shown in figure 1 


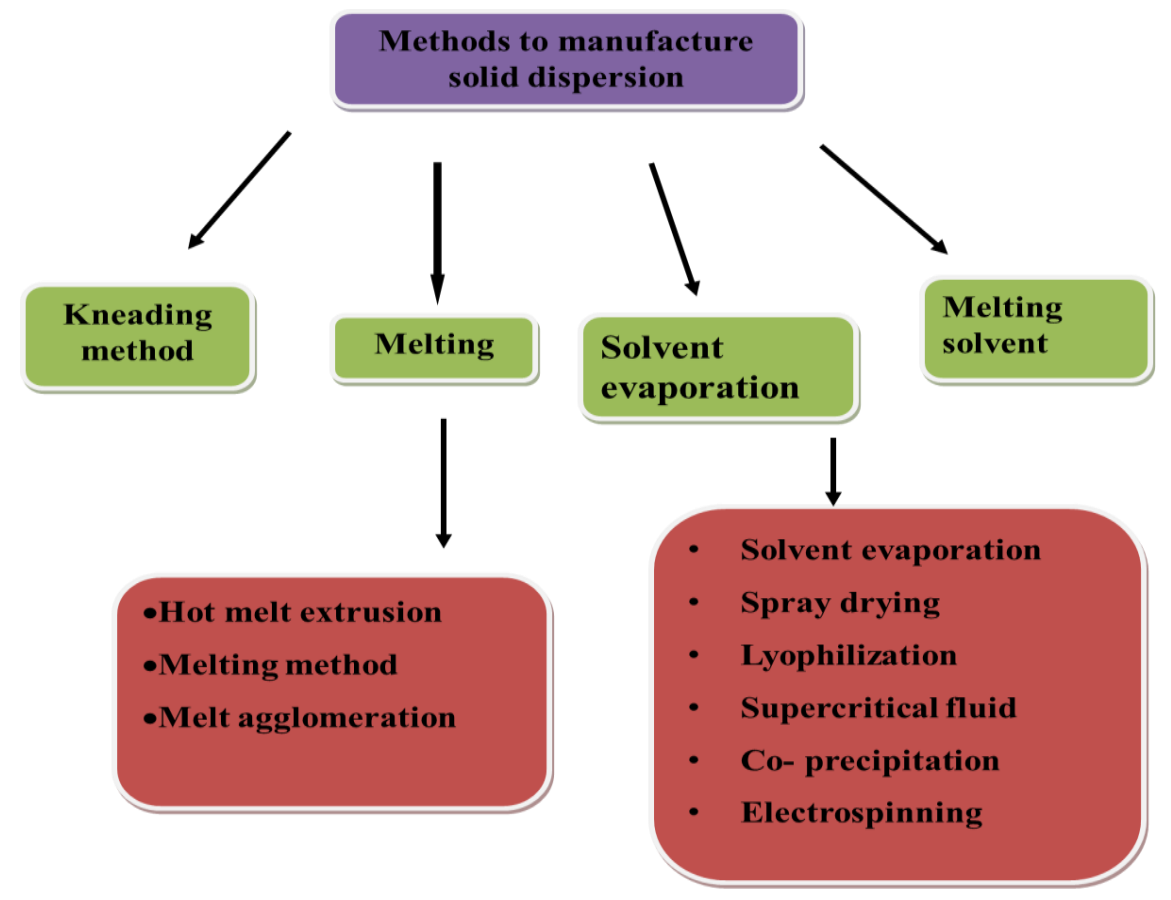

Figure 1: Various manufacturing methods of solid dispersions

\section{Solvent Evaporation:}

The solvent evaporation method is one of the most popular method used for improving solubility and dissolution of water insoluble drugs. The basic principle of this method is that drug and carrier are dissolved in a common solvent for homogeneous mixing. The main advantage of the solvent method is thermal decomposition of drugs or carriers can be prevented because of the relatively low temperatures required for the evaporation of organic solvents. ${ }^{14-15}$

Choi JS, et al develop a dutasteride (DUT) solid dispersion with various co-polymers using a solvent evaporation method to enhance its dissolution and oral bioavailability. Tocopheryl polyethylene glycol-1000-succinate was chosen as the solubilizer and microcrystalline cellulose as a carrier. There was increase in the dissolution rate and bioavailability of the drug due to the hydrogen interaction between drug and the polymer. ${ }^{16 X i a o j i n g ~ X i a, ~ e t ~ a l ~ d e v e l o p ~ a n o v e l ~}$ formulation of oleanolic acid (OA) solid dispersion (SD), using leucine (Leu) as the carrier to improve OA oral bioavailability by solvent evaporation. OA-Leu SD found to show higher relative oral bioavailability than free $0 A .{ }^{17} \mathrm{Xu}$ Cheng, et al develop Efonidipine hydrochloride solid dispersion by solvent evaporation method with HPMC-AS as matrix and urea as a $\mathrm{pH}$ adjusting agent. Excellent IVIVC for solid dispersions and crude drug was obtained for the dissolution rate. ${ }^{18}$ Shahram Emami et al develops sirolimus solid dispersions by solvent evaporation technique using Polyvinylpyrrolidone (PVP), Poloxamer 188 and Cremophore RH40. More than $75 \%$ of sirolimus was released within 30 minutes from all prepared solid dispersions. ${ }^{19}$

Jingjing Tang et al developed febuxostat (FB) solid dispersion through solvent evaporation. Solid dispersion composed of FB, polyvinylpyrrolidone (PVP K30) and poloxamer. A remarkable increase was observed of the optimised formulation in saturation solubility, dissolution studies, and bioavailability. ${ }^{20}$ Sung Jin Kim et al developed ticagrelor solid dispersion prepared via solvent evaporation method using ethanol. TPGS and Neusilin ${ }^{\circledR}$ US2 selected for preparing formulation. The released parameter of the optimized solid dispersion significantly increased in comparison with physical mixture. The solid dispersion formulation improved the peak plasma concentration $\left(\mathrm{C}_{\max }\right)$ and relative bioavailability compared to that of pure drug. ${ }^{21}$

Ahmed M Amer et al formulated candesartan cilexetil (CC) nanocrystals via solid dispersion (SD) technique using tromethamine (Tris) by solvent evaporation at different drug carrier ratios. A burst drug release followed by an improved dissolution was observed indicating instant formation of nanocrystals along with amorphization. ${ }^{22 X i n g}$ Chen et al developed solid dispersions of the poorly soluble drug progesterone (PG) using hydroxypropyl methylcellulose (HPMC), hydroxypropyl methylcellulose acetate succinate (HPMCAS), microcrystalline cellulose (MCC), polyvinylpyrrolidone (PVP) and silica $\left(\mathrm{SiO}_{2}\right)$, by, solvent evaporation (SE) and co-milling method (BM) with the aim to evaluate the impact of processing methods and carriers on the physicochemical properties of solid dispersions of PG. They concluded that, drug solubility improves by SE, but BM provides better results which clearly, indicates that intermolecular forces are more efficient than the solvent mediated.23

Dingkun Zhang et al developed Andrographolide (ADG) solid dispersion using silica ( $\mathrm{SiO} 2$ ) as a carrier by solvent evaporation method.SD formed a unique structure to disperse the drug and release drug rapidly to improve the dissolution of ADG. ${ }^{24}$ Muhammad Tayyab Ansari et al developed solid dispersions (SDs) of artemether by solvent evaporation using artemether and polyethylene glycol 6000; self-emulsified solid dispersions (SESDs) containing artemether, polyethylene glycol 6000, cremophor-A-25, olive oil, hydroxypropylmethylcellulose and transcutol. The results clearly demonstrated the increase in aqueous solubility of artemether. ${ }^{25}$

\section{Hot melt extrusion:}

Hot-melt extrusion is a method for improving solubility of poorly water-soluble drugs, in which the amorphous SD is formed without solvent. This method is carried out by a combination of the melting method and an extruder, in which drug and carriers are simultaneously mixed, heated, melted, homogenized, and extruded into rods, tablets, milled or pellets. ${ }^{26}$ Theadvantages of this technique are that it avoids the degradation of drug during the melting. ${ }^{27}$ 
Ting Wen et al developed Fenofibrate (FNB) amorphous solid dispersion employing PVP VA64 as the carrier by hotmelt extrusion method. The prepared FNB-SD was found to be an amorphous state after hot-melt extrusion process. They also concluded that, PVP VA64 could be used as a polymer to enhance the bioavailability of poorly watersoluble drugs using hot-melt extrusion. ${ }^{28}$ Yilan Zhang et al developed baicalein to prepare solid dispersions using hot melt extrusion (HME). Kollidon VA64 and Eudragit EPO were selected as two carriers. After oral administration, the relative bioavailability of solid dispersions with VA64 and EPO was found to be greater as compared with pure drug, respectively. ${ }^{29}$ Ashish L Sarode et al., developed solid dispersion of poorly water soluble drugs Indomethacin (IND), Itraconazole (ITZ), and Griseofulvin (GSF) and hydrophilic polymers - Eudragit EPO, Eudragit L-100-55, Eudragit L-100, HPMCAS-LF, HPMCAS-MF, Pharmacoat 603, and Kollidon VA- 64 by HME. The highest dissolution rate and supersaturation of poorly water-soluble drugs could be attributed to drug-polymer interactions occurred during HME. ${ }^{30}$ Uttom Nandi et al., introduced smectite clay matrices as a drug delivery carrier for the development of Indomethacin (IND) amorphous solid dispersions (ASD). Indomethacin (IND) was processed with two different smectite clays, magnesium aluminium and lithium magnesium sodium silicates, using hot melt extrusion (HME) to prepare solid dispersions. The researcher reported that amorphous solid dispersion prepared using inorganic smectite clay particles can effectively increase the dissolution rate of IND. ${ }^{31}$

Arun Butreddy et al., reviewed on approaches to overcome the solubility and bioavailability limitations of poorly soluble active pharmaceutical ingredients is the development of amorphous solid dispersions (ASDs) using hot-melt extrusion (HME) technique. It focused on the prediction of drug-polymer miscibility, the elements and sequence of $\mathrm{QbD}$, and various screening and optimization designs, to provide insights into the formulation and process variables that are encountered routinely in the production of HME-based ASDs. ${ }^{32 Z i l i n}$ Feng, et al., developed carbamazepine (CBZ) loaded SDs with Eudragit EPO as carrier by hot-melt extrusion. The results showed that, the CBZ SDs prepared by HME with CBZ and Eudragit EPO could improve the dissolution andtabletability.33Fei Yun, et al., developed osthole (OS), a coumarin derivative were prepared with various polymers including Plasdone S-630, HPMC-E5, Eudragit EPO, and Soluplus by hot-melt extrusion method. In comparison to the untreated OS coarse powder and the physical mixture with polymers, the solid dispersions prepared with Plasdone S-630 or HPMC-E5 (drug/polymer: 1:6) showed a significant enhancement of dissolution rate ( 3-fold higher D30). ${ }^{34}$ Long Xi, et al., formulated amorphous solid dispersions (ASDs) of Lacidipine using hot-melt extrusion (HME) with Soluplus and PVP VA64 at a $\mathrm{drug} /$ carrier ratio of 1:10 (w/w). In vitro dissolution rates of the optimal formulations were extremely enhanced compared to bulk Lacidipine. The ASD formulated with Soluplus showed better physical stability than that with PVP VA64. Lacidipine ASD formulated with Soluplus showed a significant increase in in vitro dissolution rate and favorable physical stability in the stress test. ${ }^{35}$ Arias MJ, et al, developed new solid dispersion system of Triamterene, a poorly soluble drug, to increase the dissolution rate and oral bioavailability. They prepared SDs by the melting carrier method using D-mannitol as matrix. ${ }^{36}$

\section{Melt agglomeration}

Melt agglomeration technique is a process where the binder acts as a carrier. $\operatorname{SD}(\mathrm{s})$ is prepared either by heating the binder, drug and excipient to a temperature above the melting point of the binder or by spraying a dispersion of drug in molten binder on the heated excipient by using a high shear mixer. ${ }^{37-38}$

Anette Seo, et al., developed solid dispersions of diazepam by melt agglomeration agglomerates in order to evaluate the possibility of improving the dissolution rate. Lactose monohydrate was melt agglomerated with polyethylene glycol (PEG) 3000 or Gelucire 50/13 (mixture of glycerides and PEG esters of fatty acids) as meltable binders in a high shear mixer. It was found to increase the dissolution rate of diazepam by melt agglomeration. A higher dissolution rate was obtained with a lower drug concentration. ${ }^{39} \mathrm{Ann}$ a Cecilia Jørgensen, et al., investigated the effect of cooling mode and storage conditions on the dissolution rate of a solid dispersion prepared by melt agglomeration. The cooling mode had an effect on the dissolution rate, probably due to several factors such as the morphology of the agglomerates and crystallinity of the carrier. The dissolution increased with increasing temperature and relative humidity which increased the amount of water sorbed in the carrier. 40

Thomas Vilhelmsen et al., developed a solid dispersions of poorly soluble drug Lu-X, by melt agglomeration in rotary processor. They investigated effects of binder type and method of manufacturing on the dissolution profile of Lu-X. Lactose monohydrate and Lu-X was melt agglomerated with Rylo MG12, Gelucire 50/13, PEG 3000, or poloxamer 188. The melt-in procedure gave a higher dissolution rate than the spray-on procedure.41 Sachin Gahoi, et al., prepared agglomerates by Atomized Melt Agglomeration (AMA) containing solid dispersion of lumefantrine. Lumefantrine and lactose were melt agglomerated using atomized molten polyethylene glycol (PEG) 6000 or Poloxamer 188 in a fluidized bed as binder/carrier. A significant enhancement in the in vitro dissolution profiles of the agglomerates was observed compared to the pure drug and drug-excipient physical mixtures. ${ }^{42}$

\section{Spray drying method}

Spray-drying commonly used method in the production of solid dispersions. It consists of dissolving or suspending the drug and carrier, and then spraying it into a stream of heated air flow to remove the solvent. Due to the large specific surface area offered by the droplets, the solvent rapidly evaporates and the solid dispersion is formed within seconds, which may be fast enough to prevent phase separation. ${ }^{43}$ Noriko Ogawa et al., prepared and characterized solid dispersion particles of Indomethacin (IMC) with amphiphilic polyvinyl caprolactam-polyvinyl acetatepolyethylene glycol graft copolymer, as a water-soluble carrier and d-mannitol (MAN) was used as an excipient by hot-melt extrusion and spray drying. The results depict that, dissolution behavior of the drug crystal could be improved by solid dispersion with the polyvinyl caprolactam-polyvinyl acetate-polyethylene glycol graft copolymer. ${ }^{44}$ Gabriela Ruphuy, et al., developed amorphous solid dispersions of ibuprofen and curcumin based on yeast glucan particles by spray drying. It was possible to produce completely amorphous composites with outstanding wettability and dispersion properties, and with significantly faster dissolution rates when compared to the micronized crude drug. ${ }^{45}$ Surendra Poudel, et al., developed a Candesartan cilexetil (CC) loaded amorphous solid dispersions with a hydrophilic carrier (PVPK30) and $\mathrm{pH}$ modifier using the spray drying technique. They found that, optimized formulation exhibited a 30,000-fold increase in solubility and a more than 9-fold enhancement in dissolution compared to pure drug. ${ }^{46}$ Varsha Pokharkar, et al., prepared pioglitazone 
solid dispersion by the spray drying method using hydrophilic polymers such as PVP K17, PVP K30, and HPMC E3. Results showed that there was significant improvement in solubility and dissolution rate in solid dispersion containing PVP K17 than in that of the pure drug. ${ }^{47}$

Annelies Smeets, et al., prepared amorphous solid dispersions of darunavir and hydroxypropyl methylcellulose (HPMC), hydroxypropyl methylcellulose acetate succinate (HPMC AS) and polyvinylpyrrolidone K-30 (PVP) with electrospraying and spray drying, in order to compare both solvent based manufacturing techniques. The formulations prepared with the two methods were amorphous and had similar characteristics concerning the residual solvent and drug release. ${ }^{48}$ Mohammed Muqtader Ahmed, et al., prepared amorphous solid dispersion (ASD) of Tadalafil (TDL) by spray-drying, using glycyrrhizin-a natural drug carrier. The optimized formulation showed marked increase in dissolution rate compared to pure TDL. ${ }^{4}$ Rahul B Chavan et al developed amorphous solid dispersion (ASD) of nisoldipine. ASD preparation from lab scale formulation technique to scalable spray drying technique. Lab scale ASDs of nisoldipine were prepared using rotary evaporation (solvent evaporation) method and the optimized stable ASDs were scaled up by spray drying. The enhanced solubility was translated to improved dissolution of the drug when compared with crystalline and amorphous form complementing the outcome of the solution state study. ${ }^{50}$

Emer Browne, et al., compared the particle characteristics and dissolution performance of amorphous solid dispersions (ASDs) of ketoprofen and vinyl-pyrrolidone based polymers prepared using electrospraying and spray drying methods. Electrospraying resulted in powders with higher specific surface area, smaller mean particle size, and narrower particle size distribution relative to the spray-dried material.51Zênia Maria MacielLavra, et al., Efavirenz solid dispersion in polyvinyl caprolactam-polyvinyl acetatepolyethylene glycol graft copolymer (Soluplus ${ }^{\circledR}$ ) using spraydrying technique. Solubility and dissolution rate of EFV was enhanced remarkably in the developed spray-dried solid dispersions, as a function of the polymer concentration. ${ }^{52}$

\section{Lyophilisation}

Lyophilisation process involves immersing the drug carrier solution in liquid nitrogen until the solution at frozen state. The best advantage is that it reduces the risk of phase separation and disadvantage is that the most of the organic solvent do not stay frozen due to low freezing temperature.53Muhammad Asad Saeed, et al., developed Artesunate solid dispersions through solvent evaporation and freeze-drying techniques using polyethylene glycol 4000 (PEG4000) as solubility enhancer. Maximum increase in solubility was attained by freeze-dried solid dispersions i.e., 2.99 folds and 2.66 folds by solvent evaporation solid dispersion as compare to pure drug. ${ }^{54}$ Lili Fitriani, et al., prepared and characterized solid dispersion of efavirenz polyvinylpyrrolidone (PVP) K-30 by freeze drying with the aim to increase its solubility. They developed solid dispersion of Efavirenz - PVP K-30 by solvent evaporation method and dried using a freeze dryer. The researcher concluded that, the solubility of solid dispersion increased significantly than solubility of pure drug. ${ }^{55}$ Mona Basha, et al., developed Famotidine(FM) solid dispersion using the novel copolymer, Soluplus ${ }^{\circledR}$ (SP) by kneading and freeze-drying techniques at various FM:SP ratios. FM solid dispersion prepared at 1:10 ratio using freeze drying manifested the highest saturation solubility, having smooth porous surface with the complete conversion of FM to the amorphous form. ${ }^{56}$ Mouhamad Khoder, et al., developed solid dispersions of prednisolone (PRD) and bovine serum albumin (BSA) by spray drying and freeze-drying methods using a PRD:BSA solution. In-vitro dissolution and release studies showed remarkable increase in dissolution profile. ${ }^{57}$

P Dangprasirt, et al., prepared solid dispersions of diclofenac sodium (DS) by freeze-drying technique, using ethylcellulose (EC) and chitosan (CS) as single and combined carriers. The solid-dispersion capsule containing 5\% Explotab was found to provide the most similar dissolution profile to the one obtained with the solid-dispersion powder.58Juan J GarcíaRodriguez, et al., developed Mebendazole (MBZ) solid dispersions containing different proportions of lowsubstituted hydroxypropylcellulose (L-HPC) by lyophilization process. In dissolution studies there is marked increase in the dissolution rate in comparison with recrystallized drug. ${ }^{59}$ Shamandeep Kaur, et al., developed Exemestane loaded phospholipid/sodium deoxycholate solid dispersions (EXE-PL/SDC-SDs) on the solubility and oral bioavailability of Exemestane by freeze dying technique. Lyophilized formulation exhibits a significant increase in solubility and dissolution rate as compared to free drug Exemestane. ${ }^{60} \mathrm{Wei}-J u a n \mathrm{Xu}$, et al., developed valsartan (VAL) SDs by a freeze-drying technique with polyethylene glycol 6000 (PEG6000) and hydroxypropylmethylcellulose as hydrophilic polymers, sodium hydroxide $(\mathrm{NaOH})$ as an alkalizer, and poloxamer 188 as a surfactant without using any organic solvents. The dissolution rates of the SDs were significantly improved at $\mathrm{pH} 1.2$ and $\mathrm{pH} 6.8$ compared to those of the pure drug. ${ }^{61}$ Khater A. S. Al-Japairai, et al., developed solid dispersion (SD) of Telmisartan formulation as a ternary mixture of a drug, a polymeric carrier (poly (vinylpyrrolidone) (PVP) K30), and an alkalizer (Na2CO3) by lyophilization. The developed SD formulations resulted in a significant improvement in in vitro dissolution compared to pure drug. ${ }^{62} \mathrm{~K}$ Wlodarski, developed tadalafil (Td) six different solid dispersions in the following polymers: HPMC, MC, PVP, PVP-VA, Kollicoat IR and Soluplus by freeze-drying. Apparent solubility and intrinsic dissolution rate studies revealed the greatest, a 16 -fold, increase in drug solubility and a significant, 20-fold, dissolution rate enhancement for the Td/PVP-VA solid dispersion in comparison with crystalline Td.63

\section{Fusion method}

In fusion technique, the molecular dispersion is formed due to the mixing caused by molecular mobility of drug and carrier molecules, which are greatest at the melting point of the two components of the dispersion.Zack Guo, et al., developed acoustic fusion to form amorphous solid dispersions (ASD) of a torcetrapib, itraconazole, and lopinavir, with a variety of polymer systems, including HPMCAS (L, M, and H), copovidone, Soluplus, PEG1500, Vitamin-E TPGS, Kolliphor EL, and Eudragit, etc. Formulations of these ASD drug products demonstrated increase in solubility of the drug substance compared to the solubility of the crystalline form of the drug.64Shamsuddin, et al., developed SD of spironolactone (SPL) using an inert carrier polyethylene glycol 4000 (PEG 4000) by the conventional fusion method. The solubility of SPL SD was found to be significantly increased as compared to SPL active pharmaceutical ingredient (API) and physical mixture of PEG 4000 and SPL. ${ }^{65}$ Guanhao Ye, et al., developed solid dispersions of itraconazole with Eudragit E100, a hydrophilic polymer, by a simple fusion method. Powdered solid dispersion and pellets prepared showed approximately 30and 70 -fold increases in dissolution rate over the pure drug, respectively. 66 
P T Koh, et al., developed solid dispersion of Efavirenz using polyethylene glycol 8000, polyvinylpyrrolidone K30 alone and combination of both by solvent and fusion method. Dissolution was remarkably improved in both systems compared to pure efavirenz. Binary and ternary solid dispersion systems both have showed a significant improvement in the dissolution rate of efavirenz. ${ }^{67}$ Rammani Prasad, et al., developed solid dispersions of furosemide with Soluplus $\AA$ by solvent evaporation and fusion methods. Solid dispersions prepared by fusion method exhibited faster drug release compared to those prepared by solvent evaporation. ${ }^{68} \mathrm{Hemanth}$ Annepogu, et al., prepared solid dispersion of thiocolchicoside (TCS) using poloxamer carriers.Poloxamer-188 was the best for increasing the solubility and release rate of TCS from the SDs. ${ }^{69} \mathrm{Amjad}$ Hussain, et al., prepare solid dispersions (SDs) of Piroxicam Solutol and Gelucire by applying fusion method. Results revealed that the solubility value of drug was increased by 20-25 times (with Solutol) and 6-10 times (with Gelucire)..$^{70}$ Mohd Aftab Alam, et al., developed effervescence assisted solid dispersion (EASD) technique by using modified fusion method by adding effervescence couple comprising organic acid (citric acid) and carbonic base (sodium bicarbonate). Solubility of atorvastatin calcium, cefuroxime axetil, clotrimazole, ketoconazole (from 16 to $500 \mu \mathrm{g} / \mathrm{ml}$ ), and metronidazole benzoate (from 112 to $208 \mu \mathrm{g} / \mathrm{ml}$ ) in EASDs was enhanced by 3.45-, 4.4-, 10.7-, 31.2-, and 1.8-fold, respectively. ${ }^{71}$

\section{Supercritical fluid technology}

Supercritical fluid methods are mostly applied with carbon dioxide (CO2), which is used as either a solvent for drug and matrix or as an anti-solvent. This technique consists of dissolving the drug and the carrier in a common solvent that is introduced into a particle formation vessel through a nozzle, simultaneously with $\mathrm{CO} 2$. When the solution is sprayed, the solvent is rapidly extracted by the SCF, resulting in the precipitation of solid dispersion particles on the walls and bottom of the vessel. The use of processes using SCF reduces particle size, residual solvent content, without any degradation and often results in high yield. ${ }^{43} \mathrm{Fei}$ Han, et al., developed solid dispersions of ibuprofen (IBU) by supercritical fluid (SCF) technology. The dissolution performance of the SCF-prepared IBU dispersions was significantly improved compared to that of the physical mixtures of crystalline IBU and a polymer. ${ }^{72}$ Bashar Altaani, et al., developed solid dispersions atorvastatin by supercritical CO2 technology by using polyvinyl pyrrolidone K30 (PVP), polyethylene glycol 6000 (PEG), Soluplus $®$, and chitosan. Dissolution enhancement of atorvastatin was achieved by preparation of polymeric dispersions of the drug using the supercritical technology without further addition of solvents. ${ }^{73}$ Jelena Djuris, et al., developed carvedilol (CARV) solid dispersions with the selected (co)polymers (polyvinylpyrrolidone (PVP), hydroxypropyl methylcellulose (HPMC), Soluplus ${ }^{\circledR}$ and Eudragit $\left.{ }^{\circledR}\right)$ with supercritical $\mathrm{CO}_{2}$ assisted method. Results confirmed with the highest dissolution efficiency of CARV-PVP and CARV-HPMC solid dispersions. ${ }^{74}$ Rana M Obaidat, et al., developed solid dispersions of tacrolimus with soluplus, PVP, HPMC, and porous chitosan with supercritical fluid technology. TPGS was used as a surfactant additive with chitosan, HPMC, and PVP. Significant improvement for the release profile was achieved for the prepared dispersions. ${ }^{75}$

Rujie Yang, et al., prepared solid dispersion (SD) of a CoQ10 by supercritical fluid technologywith fumed silica as a carrier. In vitro drug release, the dissolution of coenzyme Q10 in solid dispersion improved by $78.8 \%$ compared with commercial tablets.765eoungWook Jun, et al., developed
Cefuroxime axetil (CA) solid dispersions with HPMC 2910/PVP K-30 using solution enhanced dispersion by supercritical fluids (SEDS). Dissolution studies indicated that the dissolution rates were remarkably increased in solid dispersions compared with those in the physical mixture and drug alone. ${ }^{77}$ Jibin Guan, et al., developed solid dispersion of glyburide using supercritical fluid (SCF) technology. The glyburide silica-based dispersion could also be compressed into tablet form. In vitro drug release analysis of the silica solid dispersion tablets demonstrated faster release of glyburide compared with the commercial micronized tablet. ${ }^{78}$ Cuifang Cai, et al., developed solid dispersion (SD) of bifendate by silica as polymer using supercritical carbon dioxide (ScCO2) technology. In vitro dissolution rate was significantly improved with cumulative release of $67 \%$ within 20 min relative to $8 \%$ for the physical mixture of bifendate and silica. ${ }^{79}$

Hui Liu, et al., developed solid dispersions of budesonide by supercritical fluid (SCF) technique, using poly (ethylene oxide) (PEO) as a hydrophilic carrier. The enhanced dissolution rates of budesonide were observed from SCFtreated budesonide-PEO mixtures. budesonide-PEO solid dispersions with enhanced dissolution rate can be prepared using organic solvent-free SCF process. ${ }^{80}$ Rana M Obaidat, et al., developed cefixime trihydrate solid dispersions using conventional methods and supercritical fluid technology with different polymers (polyethylene glycol 4000 and 6000 and Soluplus. The solubility of the prepared solid dispersions increased except for those prepared with Soluplus ${ }^{\circledR}$ using supercritical fluid technology without co-solvent. The best enhancement in the release profile was recorded by Soluplus $₫$-based solid dispersions prepared using a conventional method.81Nicola De Zordi, et al., developed Furosemide solid dispersion using the hydrophilic polymer Crospovidone by supercritical anti-solvent techniques (SASs). Best in vitro dissolution performance in the simulated gastric fluid ( $\mathrm{pH}$ 1.2) was obtained, in comparison with the same SD obtained by traditional method. ${ }^{82}$

\section{Co- precipitation}

Co-precipitation is a technique for increasing the dissolution of poorly water-soluble drugs, so as to consequently improve bioavailability. ${ }^{43}$ Yiru Wang, et al., prepared solid dispersions (ASDs) of quercetin (Que) using HPMCAS-HF, HPMCAS-MF and HPMCAS-LF as carriers by co-precipitation. The Que ASD based on PVP K30 was prepared by solvent evaporation method. The Que/MF ASD exhibited better dissolution behavior compared to the Que/K30 ASD.83Amanda K.P. Mann, et al., developed amorphous solid dispersions of compound A, and copovidone were made by conventional spray drying and co-precipitation. The amorphous dispersions were then formulated and tableted. The coprecipitation tablets had slightly slower dissolution than the spray-dried dispersion. ${ }^{84}$

Zedong Dong, etal.,developed solid dispersions of Compound A in Hypromellose acetate succinate (HPMC-AS) prepared by hot-melt extrusion (HME) and solvent co-precipitation (CP) processes. Dissolution study showed that the $\mathrm{CP}$ product had a faster dissolution profile, but slower intrinsic dissolution rate than the HME product. ${ }^{85}$ Sonal $\mathrm{V}$ Bhujbal, et al., developed amorphous solid dispersion (ASD) of lumefantrine with spray anti-solvent precipitation using hydroxypropylmethylcellulose phthalate (HPMCP), hydroxypropylmethylcellulose acetate succinate (HPMCAS), poly(methacrylic acid-ethyl acrylate) (EL100) and cellulose acetate phthalate (CAP) as excipients at various drugpolymer ratios. HPMCP and HPMCAS ASDs also achieved 
greater drug release levels in the dissolution study than other polymers. ${ }^{86}$

DalwadiSonali, et al., developed silymarin solid dispersions using HPMC E $15 \mathrm{LV}$ by kneading, spray drying and coprecipitation methods. Increase in dissolution compared to pure drug was found as: co-precipitation > spray drying > kneading methodology. The co-precipitation method proved to be best and provided a stable amorphous solid dispersion with improved dissolution compared to the pure drug. ${ }^{87} \mathrm{Hao}$ HelenHou, et al., developed amorphous solid dispersion of GDC-0810 using spray drying, coprecipitation using overhead mixing and coprecipitation using resonant acoustic mixing to generate amorphous solid dispersions (ASDs) of 50\% GDC-0810 with hydroxypropyl methylcellulose acetate succinate. Coprecipitated ASD powders (overhead mixing and resonant acoustic mixing) demonstrated superior tabletability and flow properties when compared to the spray drying powder. 88

\section{Electrospinning}

Electrospinning is one of the novel and popular method in solid dispersion due to its effectiveness, low cost, and the properties of the electrospun nanoproducts. ${ }^{89}$

This method uses electrical energy to induce changes from liquid to solid where, the drug - polymer solution is subjected to potential between 5 and $30 \mathrm{kV}$ and when electric field removes the surface tension of the drug/polymer solution at the air interface, fibers of submicron diameters are formed. ${ }^{90-91}$

Ahmad Ziaee, et al., developed amorphous solid dispersion (ASD) of ibuprofen (IBU) with two cellulosic excipients, HPMCAS and HPMCP-HP55 employing electrospinning (ES), spray-drying (SD) and rotary evaporation (RE) solventbased techniques. Dissolution studies showed that electrospun samples had the highest API release rate due to their fibrous morphology and higher specific surface area. ${ }^{92}$ Zsombor K Nagy, et al., developed itraconazole (ITRA) with PVPVA64 matrix polymer using four different solventbased methods such asHigh-speed electrospinning (HSES), single-needle electrospinning (SNES), spray drying (SD) and film casting (FC). The results comfirmed the improvement in dissolution of crystalline ITRA. ${ }^{93}$ Edina Szabó, et al., developed amorphous solid dispersions (ASDs) of spironolactone and poly(vinylpyrrolidone-co-vinyl acetate) with drug-loaded electrospun (ES) and spray-dried (SD) materials from dichloromethane and ethanol-containing solutions. ${ }^{44}$ BalázsDémuth, et al., developed solid dispersions of itraconazole [ITR] containing polyvinylpyrrolidone-vinyl acetate. Magnesium stearate acted as a nucleation promoting agent. The extent of dissolution of more than $95 \%$ was realizable when a less hydrophobic lubricant, sodium stearyl fumarate (soluble in the medium), was applied. ${ }^{95}$ Laura Modica de Mohac, et al., reviewed on the emerging trends in the generation of amorphous and micro/nano-crystalline solid dispersions using electrospinning to improve the dissolution rate and in turn the bioavailability of poorly water-soluble drugs. ${ }^{96}$ DengGuang Yu, et al., reviewed the development, advantages and pharmaceutical applications of electrospinning for producing polymeric ASDs. These advanced systems can improve dissolution behaviour and provide programmable drug release profiles.97Tibor Casian, et al., developed meloxicam based amorphous solid dispersion through electrospinning technique by using Eudragit $\mathrm{E}$ as carrier compared to PVPk30 where a DMF: THF solvent system was suitable. Microflux dissolution-permeation studies showed a significantly higher diffusion from amorphous solid dispersions compared to crystalline meloxicam. ${ }^{98}$

The overall techniques for the solid dispersions have been summarized in table 1.

Table 1" Summary related to overall techniques used recently with continually used polymer

\begin{tabular}{|c|c|c|c|}
\hline SD Techniques & Drugs & Polymers & Ref. \\
\hline \multirow{9}{*}{$\begin{array}{l}\text { Solvent } \\
\text { evaporation }\end{array}$} & Dutasteride (DUT) & Microcrystalline cellulose & {$[16]$} \\
\hline & Oleanolic acid $(\mathrm{OA})$ & Leucine & {$[17]$} \\
\hline & Efonidipine hydrochloride & HPMC-AS & {$[18]$} \\
\hline & Sirolimus & Polyvinylpyrrolidone (PVP), Poloxamer 188 and Cremophore RH40 & {$[19]$} \\
\hline & Febuxostat (FB) & Polyvinylpyrrolidone (PVP K30) and poloxamer & {$[20]$} \\
\hline & Ticagrelor & TPGS and Neusilin® US2 & {$[21]$} \\
\hline & Candesartan cilexetil (CC) & Tromethamine (Tris) & {$[22]$} \\
\hline & Progesterone (PG) & $\begin{array}{l}\text { Hydroxypropyl methylcellulose (HPMC), Hydroxypropyl } \\
\text { methylcellulose acetate succinate (HPMCAS), Microcrystalline } \\
\text { cellulose (MCC), Polyvinylpyrrolidone (PVP) and silica }\left(\mathrm{SiO}_{2}\right)\end{array}$ & [23] \\
\hline & Andrographolide (ADG) & Silica (SiO2) & {$[24]$} \\
\hline \multirow{6}{*}{$\begin{array}{l}\text { Hot melt } \\
\text { extrusion }\end{array}$} & Fenofibrate (FNB) & PVP VA64 & [28] \\
\hline & Baicalein & Kollidon VA64 and Eudragit EPO & [29] \\
\hline & $\begin{array}{l}\text { Indomethacin (IND), } \\
\text { Itraconazole (ITZ), and } \\
\text { Griseofulvin (GSF) }\end{array}$ & $\begin{array}{l}\text { Eudragit EPO, Eudragit L-100-55, Eudragit L-100, HPMCAS-LF, } \\
\text { HPMCAS-MF, Pharmacoat 603, and Kollidon VA-64 }\end{array}$ & [30] \\
\hline & Indomethacin (IND) & Magnesium aluminium and lithium magnesium sodium silicates & [31] \\
\hline & Carbamazepine (CBZ) & Eudragit EPO & [33] \\
\hline & Osthole (OS) & Plasdone S-630, HPMC-E5, Eudragit EPO, and Soluplus & [34] \\
\hline
\end{tabular}




\begin{tabular}{|c|c|c|c|}
\hline & Lacidipine & Soluplus and PVP VA64 & [35] \\
\hline & Triamterene & D-mannitol & [36] \\
\hline \multirow{3}{*}{$\begin{array}{l}\text { Melt } \\
\text { agglomeration }\end{array}$} & Diazepam & Polyethylene glycol (PEG) 3000 or Gelucire 50/13 & [39] \\
\hline & Lu-X & Rylo MG12, Gelucire 50/13, PEG 3000, or poloxamer 188 & [41] \\
\hline & Lumefantrine & Polyethylene glycol (PEG) 6000 or Poloxamer 188 & {$[42]$} \\
\hline \multirow{9}{*}{$\begin{array}{l}\text { Spray drying } \\
\text { method }\end{array}$} & Indomethacin (IMC) & Polyvinyl caprolactam-polyvinyl acetate-polyethylene glycol & {$[44]$} \\
\hline & Ibuprofen & Curcumin & [45] \\
\hline & Candesartan cilexetil (CC) & PVPK30 & [46] \\
\hline & Pioglitazone & PVP K17, PVP K30, and HPMC E3 & [47] \\
\hline & Darunavir & $\begin{array}{l}\text { Hydroxypropyl methylcellulose (HPMC), hydroxypropyl } \\
\text { methylcellulose acetate succinate (HPMC AS) and } \\
\text { polyvinylpyrrolidone K-30 (PVP) }\end{array}$ & [48] \\
\hline & Tadalafil (TDL) & Glycyrrhizin & [49] \\
\hline & Nisoldipine & Polyethylene glycol 4000 (PEG4000) & {$[50]$} \\
\hline & Ketoprofen & vinyl-pyrrolidone based polymers & [51] \\
\hline & Efavirenz & $\begin{array}{l}\text { Polyvinyl caprolactam-polyvinyl acetate-polyethylene glycol graft } \\
\text { copolymer (Soluplus }^{\circledR} \text { ) }\end{array}$ & {$[52]$} \\
\hline \multirow[t]{9}{*}{ Lyophilization } & Efavirenz & Polyvinylpyrrolidone (PVP) K-30 & [55] \\
\hline & Famotidine & Soluplus ${ }^{\circledR}(\mathrm{SP})$ & [56] \\
\hline & Prednisolone & Bovine serum albumin (BSA) & [57] \\
\hline & Diclofenac sodium (DS) & Ethylcellulose (ECand chitosan (CS)) & [58] \\
\hline & Mebendazole (MBZ) & low-substituted hydroxypropylcellulose (L-HPC) & [59] \\
\hline & Exemestane & Phospholipid/sodium deoxycholate & {$[60]$} \\
\hline & Valsartan (VAL) & $\begin{array}{l}\text { Polyethylene glycol } 6000 \text { (PEG6000) and } \\
\text { hydroxypropylmethylcellulose }\end{array}$ & {$[61]$} \\
\hline & Telmisartan & Polyvinylpyrrolidone (PVP) K30 & {$[62]$} \\
\hline & Tadalafil (Td) & HPMC, MC, PVP, PVP-VA, Kollicoat IR and Soluplus & {$[63]$} \\
\hline \multirow[t]{13}{*}{ Fusion method } & $\begin{array}{l}\text { Torcetrapib, itraconazole, } \\
\text { and lopinavir }\end{array}$ & $\begin{array}{l}\text { HPMCAS (L, M, and H), copovidone, Soluplus, PEG1500, Vitamin-E } \\
\text { TPGS, Kolliphor EL, and Eudragit }\end{array}$ & {$[64]$} \\
\hline & Spironolactone (SPL) & Polyethylene glycol 4000 (PEG 4000) & [65] \\
\hline & Itraconazole & Eudragit E100 & [66] \\
\hline & Efavirenz & Polyethylene glycol8000, polyvinylpyrrolidone K30 & [67] \\
\hline & Thiocolchicoside (TCS) & Poloxamer-188 & [69] \\
\hline & Piroxicam & Solutol and Gelucire & {$[70]$} \\
\hline & $\begin{array}{l}\text { Atorvastatin calcium, } \\
\text { cefuroxime axetil, } \\
\text { clotrimazole, } \\
\text { ketoconazole and } \\
\text { metronidazole benzoate }\end{array}$ & Citric acid and sodium bicarbonate & {$[71]$} \\
\hline & Atorvastatin & $\begin{array}{l}\text { Polyvinyl pyrrolidone K30 (PVP), polyethylene glycol } 6000 \text { (PEG), } \\
\text { Soluplus®, and chitosan }\end{array}$ & {$[73]$} \\
\hline & Carvedilol (CARV) & $\begin{array}{l}\text { Polyvinylpyrrolidone (PVP), hydroxypropyl methylcellulose (HPMC), } \\
\text { Soluplus } ₫ \text { and Eudragit }{ }^{\circledR}\end{array}$ & {$[74]$} \\
\hline & Cefuroxime axetil (CA) & Silica & {$[77]$} \\
\hline & Glyburide & Silica & {$[78]$} \\
\hline & Bifendate & Poly (ethylene oxide) (PEO) & {$[79]$} \\
\hline & Budesonide & Polyethylene glycol 4000 and 6000 and & {$[80]$} \\
\hline
\end{tabular}




\begin{tabular}{|c|c|c|c|}
\hline & Cefixime trihydrate & Soluplus & {$[81]$} \\
\hline & Furosemide & Crospovidone & [82] \\
\hline \multirow{4}{*}{$\begin{array}{l}\text { Co- } \\
\text { precipitation } \\
\text { method }\end{array}$} & Quercetin (Que) & HPMCAS-HF, HPMCAS-MF and HPMCAS-LF & [83] \\
\hline & Lumefantrine & $\begin{array}{l}\text { HydroxypropylmethylcellulosePhthalate (HPMCP), } \\
\text { hydroxypropylmethylcellulose acetate succinate (HPMCAS), poly } \\
\text { (methacrylic acid-ethyl acrylate) (EL100) and cellulose acetate } \\
\text { phthalate (CAP) }\end{array}$ & [86] \\
\hline & Silymarin & HPMC E 15LV & [87] \\
\hline & GDC-0810 & Hydroxypropyl methylcellulose acetate succinate & [88] \\
\hline \multirow[t]{5}{*}{ Electrospinning } & Ibuprofen (IBU) & HPMCAS and HPMCP-HP55 & [92] \\
\hline & Itraconazole (ITRA) & PVPVA64 & [93] \\
\hline & Spironolactone & Poly (vinylpyrrolidone-co-vinyl acetate) & [94] \\
\hline & Itraconazole [ITR] & Polyvinylpyrrolidone-vinyl acetate & [95] \\
\hline & Meloxicam & Eudragit E & [98] \\
\hline
\end{tabular}

\section{CONCLUSION}

Solid dispersions are one of the systematic technologies for controlling many problems relating to bioavailability of poorly soluble drug. Still, there has some problem which will be short out by applying novel and present approach. This review focuses on current attempt to short out bioavailability issue and explains various new technologies involved for development of SD. With each continuing approach, we believe that the SD systems will continue to be utilized for formulating poorly soluble drugs.

\section{REFERENCES}

1. Dressman JB, Thelen K, Jantratid E. Towards quantitative prediction of oral drug absorption. Clin Pharmacokinet. 2008; 47(10):655-67. https://doi.org/10.2165/00003088200847100-00003

2. Huang Y, Dai WG. Fundamental aspects of solid dispersion technology for poorly soluble drugs. Acta Pharmaceutica Sinica B. 2014 Feb $1 ; 4(1): 18-25$ https://doi.org/10.1016/j.apsb.2013.11.001

3. Ezawa, T., Inoue, Y., Murata, I., Takao, K., Sugita, Y. and Kanamoto, I. Characterization of the dissolution behavior of piperine/cyclodextrins inclusion complexes. AAPS PharmSciTech, 2018; 19(2):933. https://doi.org/10.1208/s12249-017-0908-9

4. Cagel M, Tesan FC, Bernabeu E, Salgueiro MJ, Zubillaga MB, Moretton MA, Chiappetta DA. Polymeric mixed micelles as nanomedicines: Achievements and perspectives. European Journal of Pharmaceutics and Biopharmaceutics. 2017 Apr 1; 113:211-28. https://doi.org/10.1016/j.ejpb.2016.12.019

5. Vo CL, Park C, Lee BJ. Current trends and future perspectives of solid dispersions containing poorly water-soluble drugs. European journal of pharmaceutics and biopharmaceutics. 2013 Nov 1; 85(3):799-813. https://doi.org/10.1016/j.ejpb.2013.09.007

6. Choi JS, Lee SE, Jang WS, Byeon JC, Park JS. Solid dispersion of dutasteride using the solvent evaporation method: Approaches to improve dissolution rate and oral bioavailability in rats. Materials Science and Engineering: C. 2018 Sep 1; 90:387-96. https://doi.org/10.1016/j.msec.2018.04.074

7. Liu X, Feng X, Williams RO, Zhang F. Characterization of amorphous solid dispersions. Journal of Pharmaceutical Investigation. $2018 \mathrm{Jan}$; 48(1):19-41. https://doi.org/10.1007/s40005-017-0361-5

8. Bhatnagar P, Dhote V, Chandra Mahajan S, Kumar Mishra P, Kumar Mishra D. Solid dispersion in pharmaceutical drug development: from basics to clinical applications. Current drug delivery. 2014 Apr 1; 11(2):155-71.

https://doi.org/10.2174/15672018113109990044

9. Zhang $X$, Xing H, Zhao Y, Ma Z. Pharmaceutical dispersion techniques for dissolution and bioavailability enhancement of poorly water-soluble drugs. Pharmaceutics. 2018 Sep; 10(3):74 https://doi.org/10.3390/pharmaceutics10030074

10. Meng F, Gala U, Chauhan H. Classification of solid dispersions: correlation to (i) stability and solubility (ii) preparation and characterization techniques. Drug development and industrial pharmacy. 2015 Sep 2; 41(9):1401-15. https://doi.org/10.3109/03639045.2015.1018274

11. Huang J, Wigent RJ, Bentzley CM, Schwartz JB. Nifedipine solid dispersion in microparticles of ammonio methacrylate copolymer and ethylcellulose binary blend for controlled drug delivery: Effect of drug loading on release kinetics. International journal of pharmaceutics. 2006 Aug 17; 319(1-2):44-54. https://doi.org/10.1016/j.ijpharm.2006.03.035

12. Damian F, Blaton N, Naesens L, Balzarini J, Kinget R, Augustijns P, Van den Mooter G. Physicochemical characterization of solid dispersions of the antiviral agent UC-781 with polyethylene glycol 6000 and Gelucire 44/14. European Journal of Pharmaceutical Sciences. 2000 Jun 1; 10(4):311-22. https://doi.org/10.1016/S0928-0987(00)00084-1

13. Wadher KJ, Kakde RB, Umekar MJ. Formulation and evaluation of sustained release matrix tablets of metformin hydrochloride using $\mathrm{pH}$ dependent and $\mathrm{pH}$ independent methacrylate polymers. Journal of Pharmaceutical Research International. 2011 Apr 8:29-45. https://doi.org/10.9734/BJPR/2011/255

14. Singh J, Walia M, Harikumar SL. Solubility enhancement by solid dispersion method: a review. Journal of drug delivery and Therapeutics. 2013 Sep 14; 3(5):148-55 https://doi.org/10.22270/jddt.v3i5.632

15. Tran P, Pyo YC, Kim DH, Lee SE, Kim JK, Park JS. Overview of the manufacturing methods of solid dispersion technology for improving the solubility of poorly water-soluble drugs and application to anticancer drugs. Pharmaceutics. 2019 Mar; 11(3):132. https://doi.org/10.3390/pharmaceutics11030132

16. Choi JS, Lee SE, Jang WS, Byeon JC, Park JS. Solid dispersion of dutasteride using the solvent evaporation method: Approaches to improve dissolution rate and oral bioavailability in rats. Materials Science and Engineering: C. 2018 Sep 1; 90:387-96. https://doi.org/10.1016/j.msec.2018.04.074

17. Xia X, Tan Z, Fan Y, Hu Y, Deng J. Preparation and evaluation of a novel solid dispersion using leucine as carrier. Journal of Pharmacy and Pharmacology. 2020 Feb; 72(2):175-84. https://doi.org/10.1111/jphp.13200 
18. Cheng X, Gao J, Li J, Cheng G, Zou M, Piao H. In Vitro-In Vivo Correlation for Solid Dispersion of a Poorly Water-Soluble Drug Efonidipine Hydrochloride. AAPS PharmSciTech. 2020 Jul; 21:16. https://doi.org/10.1208/s12249-020-01685-1

19. Emami S, Valizadeh H, Islambulchilar Z, Zakeri-Milani P. Development and physicochemical characterization of sirolimus solid dispersions prepared by solvent evaporation method. Advanced pharmaceutical bulletin. 2014 Dec; 4(4):369.

20. Tang J, Bao J, Shi X, Sheng X, Su W. Preparation, optimisation, and in vitro-in vivo evaluation of febuxostat ternary solid dispersion. Journal of microencapsulation. 2018 Jul 4; 35(5):454-66. https://doi.org/10.1080/02652048.2018.1526339

21. Kim SJ, Lee HK, Na YG, Bang KH, Lee HJ, Wang M, Huh HW, Cho CW. A novel composition of ticagrelor by solid dispersion technique for increasing solubility and intestinal permeability. International journal of pharmaceutics. 2019 Jan 30; 555:11-8. https://doi.org/10.1016/j.ijpharm.2018.11.038

22. Amer AM, Allam AN, Abdallah OY. Preparation, characterization and ex vivo-in vivo assessment of candesartan cilexetil nanocrystals via solid dispersion technique using an alkaline esterase activator carrier. Drug development and industrial pharmacy. 2019 Jul 3; 45(7):1140-8. https://doi.org/10.1080/03639045.2019.1600533

23. Chen X, Partheniadis I, Nikolakakis I, Al-Obaidi H. Solubility improvement of progesterone from solid dispersions prepared by solvent evaporation and co-milling. Polymers. $2020 \mathrm{Apr}$; 12(4):854. https://doi.org/10.3390/polym 12040854

24. Zhang D, Lin J, Zhang F, Han X, Han L, Yang M, Zou W. Preparation and evaluation of andrographolide solid dispersion vectored by silicon dioxide. Pharmacognosy magazine. 2016 May; 12(Suppl 2): S245. https://doi.org/10.4103/0973-1296.182156

25. Tayyab Ansari M, Arshad MS, Hussain A, Ahmad Z. Improvement of solubility, dissolution and stability profile of artemether solid dispersions and self-emulsified solid dispersions by solvent evaporation method. Pharmaceutical development and technology. 2018 Nov 26; 23(10):1007-15. https://doi.org/10.1080/10837450.2016.1265554

26. Genina N, Hadi B, Löbmann K. Hot melt extrusion as solvent-free technique for a continuous manufacturing of drug-loaded mesoporous silica. Journal of pharmaceutical sciences. 2018 Jan 1; 107(1):149-55. https://doi.org/10.1016/j.xphs.2017.05.039

27. Nikam VK, Shete SK, Khapare JP. Most promising solid dispersion technique of oral dispersible tablet. Beni-Suef University Journal of Basic and Applied Sciences. 2020 Dec; 9(1):1-6. https://doi.org/10.1186/s43088-020-00086-4

28. Wen T, Niu B, Wu Q, Zhou Y, Pan X, Quan G, Wu C. Fenofibrate Solid Dispersion Processed by Hot-Melt Extrusion: Elevated Bioavailability and Its Cell Transport Mechanism. Current drug delivery. 2019 Jan 1; 16(6):538-47. https://doi.org/10.2174/1567201816666190122123044

29. Zhang Y, Luo R, Chen Y, Ke X, Hu D, Han M. Application of carrier and plasticizer to improve the dissolution and bioavailability of poorly water-soluble baicalein by hot melt extrusion. AAPS PharmSciTech. 2014 Jun; 15(3):560-8. https://doi.org/10.1208/s12249-013-0071-x

30. Sarode AL, Sandhu H, Shah N, Malick W, Zia H. Hot melt extrusion (HME) for amorphous solid dispersions: predictive tools for processing and impact of drug-polymer interactions on supersaturation. European Journal of Pharmaceutical Sciences. 2013 Feb 14; 48(3):371-84.

https://doi.org/10.1016/j.ejps.2012.12.012

31. Nandi U, Mithu MS, Hurt AP, Trivedi V, Douroumis D. DrugSmectite Clay Amorphous Solid Dispersions Processed by Hot Melt Extrusion. AAPS PharmSciTech. 2020 Oct; 21(7):1-0. https://doi.org/10.1208/s12249-020-01813-x

32. Butreddy A, Bandari S, Repka MA. Quality-by-design in hot melt extrusion based amorphous solid dispersions: An industrial perspective on product development. European Journal of
Pharmaceutical Sciences. 2020 Nov 28:105655.

https://doi.org/10.1016/j.ejps.2020.105655

33. Feng Z, Li M, Wang W. Improvement of dissolution and tabletability of carbamazepine solid dispersions with high drug loading prepared by hot-melt extrusion. Die Pharmazie-An International Journal of Pharmaceutical Sciences. 2019 Sep 1 74(9):523-8

34. Yun F, Kang A, Shan J, Zhao X, Bi X, Li J, Di L. Preparation of osthole-polymer solid dispersions by hot-melt extrusion for dissolution and bioavailability enhancement. International journal of pharmaceutics. 2014 Apr 25; 465(1-2):436-43. https://doi.org/10.1016/j.ijpharm.2014.02.040

35. Xi L, Song H, Wang Y, Gao H, Fu Q. Lacidipine amorphous solid dispersion based on hot melt extrusion: good miscibility, enhanced dissolution, and favorable stability. AAPS PharmSciTech. 2018 Oct; 19(7):3076-84. https://doi.org/10.1208/s12249-018-1134-9

36. Arias MJ, Gines JM, Moyano JR, Rabasco AM. The application of solid dispersion technique with D-mannitol to the improvement in oral absorption of triamterene. Journal of drug targeting. 1994 Jan $1 ; 2(1): 45-51$. https://doi.org/10.3109/10611869409015892

37. Nikghalb LA, Singh G, Singh G, Kahkeshan KF. Solid Dispersion: Methods and Polymers to increase the solubility of poorly soluble drugs. Journal of Applied Pharmaceutical Science. 2012 Oct; 2(10):170-5.

38. Kaur J, Aggarwal G, Singh G, Rana AC. Improvement of drug solubility using solid dispersion. Int J Pharm Pharm Sci. 2012 $4(2): 47-53$.

39. Seo A, Holm P, Kristensen HG, Schæfer T. The preparation of agglomerates containing solid dispersions of diazepam by melt agglomeration in a high shear mixer. International Journal of Pharmaceutics. 2003 Jun 18; 259(1-2):161-71. https://doi.org/10.1016/S0378-5173(03)00228-X

40. Jørgensen AC, Torstenson AS. Humid storage conditions increase the dissolution rate of diazepam from solid dispersions prepared by melt agglomeration. Pharmaceutical development and technology. 2008 Jan 1; 13(3):187-95. https://doi.org/10.1080/10837450801949384

41. Vilhelmsen T, Eliasen H, Schæfer T. Effect of a melt agglomeration process on agglomerates containing solid dispersions. International journal of pharmaceutics. 2005 Oct 13; 303(1-2):132-42. https://doi.org/10.1016/j.ijpharm.2005.07.012

42. Gahoi S, Jainc GK, Singhalc M, Warsic MH, Mallickc N, Kharc RK, Ahmadc FJ. Atomized Melt Agglomeration of Lumefantrine: Improvement in Dissolution Characteristics. Journal of Pharmacy Research. 2011 May; 4(5):1520-3.

43. Patil RM, Maniyar AH, Kale MT, Akarte AM, Baviskar DT. Solid dispersion: strategy to enhance solubility. Cheminform. 2012 Jun 5; 43(23): no. https://doi.org/10.1002/chin.201223244

44. Ogawa N, Hiramatsu T, Suzuki R, Okamoto R, Shibagaki K, Fujita $\mathrm{K}$, Takahashi C, Kawashima Y, Yamamoto H. Improvement in the water solubility of drugs with a solid dispersion system by spray drying and hot-melt extrusion with using the amphiphilic polyvinyl caprolactam-polyvinyl acetate-polyethylene glycol graft copolymer and d-mannitol. European Journal of Pharmaceutical Sciences. 2018 Jan 1; 111:205-14. https://doi.org/10.1016/j.ejps.2017.09.014

45. Ruphuy G, Saloň I, Tomas J, Šalamúnová P, Hanuš J, Štěpánek F. Encapsulation of poorly soluble drugs in yeast glucan particles by spray drying improves dispersion and dissolution properties. International journal of pharmaceutics. 2020 Feb 25; 576:118990. https://doi.org/10.1016/j.ijpharm.2019.118990

46. Poudel S, Kim DW. Developing pH-Modulated Spray Dried Amorphous Solid Dispersion of Candesartan Cilexetil with Enhanced In Vitro and In Vivo Performance. Pharmaceutics. 2021 Apr; 13(4):497. https://doi.org/10.3390/pharmaceutics13040497 
47. Pokharkar V, Kutwal M, Mandpe L. Pioglitazone solid dispersion system prepared by spray drying method: in vitro and in vivo evaluation. PDA journal of pharmaceutical science and technology. 2013 Jan 1; 67(1):23-34. https://doi.org/10.5731/pdajpst.2013.00899

48. Smeets A, Koekoekx R, Clasen C, Van den Mooter G. Amorphous solid dispersions of darunavir: Comparison between spray drying and electrospraying. European Journal of Pharmaceutics and Biopharmaceutics. 2018 Sep 1; 130:96-107. https://doi.org/10.1016/j.ejpb.2018.06.021

49. Ahmed MM, Fatima F, Kalam MA, Alshamsan A, Soliman GA, Shaikh AA, Alshahrani SM, Aldawsari MF, Bhatia S, Anwer MK. Development of spray-dried amorphous solid dispersions of tadalafil using glycyrrhizin for enhanced dissolution and aphrodisiac activity in male rats. Saudi Pharmaceutical Journal. 2020 Dec $1 ; 28(12): 1817-26$.

https://doi.org/10.1016/j.jsps.2020.11.007

50. Chavan RB, Lodagekar A, Yadav B, Shastri NR. Amorphous solid dispersion of nisoldipine by solvent evaporation technique: preparation, characterization, in vitro, in vivo evaluation, and scale up feasibility study. Drug delivery and translational research. 2020 Aug; 10(4):903-18. https://doi.org/10.1007/s13346-020-00775-8

51. Browne E, Charifou R, Worku ZA, Babu RP, Healy AM. Amorphous solid dispersions of ketoprofen and poly-vinyl polymers prepared via electrospraying and spray drying: A comparison of particle characteristics and performance. International journal of pharmaceutics. 2019 Jul 20; 566:173-84.

https://doi.org/10.1016/j.ijpharm.2019.05.062

52. Lavra ZM, Pereira de Santana D, Ré MI. Solubility and dissolution performances of spray-dried solid dispersion of Efavirenz in Soluplus. Drug development and industrial pharmacy. 2017 Jan 2; 43(1):42-54

https://doi.org/10.1080/03639045.2016.1205598

53. Xu WJ, Xie HJ, Cao QR, Shi LL, Cao Y, Zhu XY, Cui JH. Enhanced dissolution and oral bioavailability of valsartan solid dispersions prepared by a freeze-drying technique using hydrophilic polymers. Drug delivery. 2016 Jan 2; 23(1):41-8. https://doi.org/10.3109/10717544.2014.903012

54. Saeed MA, Ansari MT, Ch BA. Enhancement of solubility and dissolution profile of artesunate by employing solid dispersion approach: An in-vitro evaluation. Pakistan journal of pharmaceutical sciences. 2019 Jan 15; 36(1SI):353-62.

55. Fitriani L, Haqi A, Zaini E. Preparation and characterization of solid dispersion freeze-dried efavirenz-polyvinylpyrrolidone $\mathrm{K}$ 30. Journal of advanced pharmaceutical technology \& research. 2016 Jul; 7(3):105. https://doi.org/10.4103/2231-4040.184592

56. Basha M, Salama A, Noshi SH. Soluplus $₫$ based solid dispersion as fast disintegrating tablets: a combined experimental approach for enhancing the dissolution and antiulcer efficacy of famotidine. Drug development and industrial pharmacy. 2020 Feb $1 ; 46(2): 253-63$ https://doi.org/10.1080/03639045.2020.1716376

57. Khoder M, Abdelkader H, ElShaer A, Karam A, Najlah M, Alany RG. The use of albumin solid dispersion to enhance the solubility of unionizable drugs. Pharmaceutical development and technology. 2018 Aug 9; 23(7):732-8. https://doi.org/10.1080/10837450.2017.1364267

58. Dangprasirt P, Pongwai S. Development of diclofenac sodiumcontrolled release solid dispersion powders and capsules by freeze drying technique using ethylcellulose and chitosan as carriers. Drug development and industrial pharmacy. 1998 Jan $1 ; 24(10): 947-53$. https://doi.org/10.3109/03639049809097274

59. García-Rodriguez JJ, Paloma M, Vegas-Sánchez MC, TorradoDurán S, Bolás-Fernández F, Torrado-Santiago S. Changed crystallinity of mebendazole solid dispersion: improved anthelmintic activity. International journal of pharmaceutics. 2011 Jan 17; 403(1-2):23-8. https://doi.org/10.1016/j.ijpharm.2010.10.002
60. Kaur S, Jena SK, Samal SK, Saini V, Sangamwar AT. Freeze dried solid dispersion of exemestane: A way to negate an aqueous solubility and oral bioavailability problems. European Journal of Pharmaceutical Sciences. 2017 Sep 30; 107:54-61. https://doi.org/10.1016/j.ejps.2017.06.032

61. Xu WJ, Xie HJ, Cao QR, Shi LL, Cao Y, Zhu XY, Cui JH. Enhanced dissolution and oral bioavailability of valsartan solid dispersions prepared by a freeze-drying technique using hydrophilic polymers. Drug delivery. 2016 Jan 2; 23(1):41-8. https://doi.org/10.3109/10717544.2014.903012

62. Al-Japairai KA, Alkhalidi HM, Mahmood S, Almurisi SH, Doolaanea AA, Al-Sindi TA, Chatterjee B. Lyophilized Amorphous Dispersion of Telmisartan in a Combined Carrier-Alkalizer System: Formulation Development and In Vivo Study. ACS omega. 2020 Dec 10; 5(50):32466-80. https://doi.org/10.1021/acsomega.0c04588

63. Wlodarski K, Sawicki WI, Haber K, Knapik J, Wojnarowska Z, Paluch M, Lepek P, Hawelek L, Tajber L. Physicochemical properties of tadalafil solid dispersions-Impact of polymer on the apparent solubility and dissolution rate of tadalafil. European Journal of Pharmaceutics and Biopharmaceutics. 2015 Aug 1; 94:106-15. https://doi.org/10.1016/j.ejpb.2015.04.031

64. Guo Z, Boyce C, Rhodes T, Liu L, Salituro GM, Lee KJ, Bak A, Leung DH. A novel method for preparing stabilized amorphous solid dispersion drug formulations using acoustic fusion. International Journal of Pharmaceutics. 2021 Jan 5; 592:120026. https://doi.org/10.1016/j.ijpharm.2020.120026

65. Shamsuddin MF, Ansari SH, Ali J. Development and evaluation of solid dispersion of spironolactone using fusion method. International journal of pharmaceutical investigation. 2016 Jan 6(1):63. https://doi.org/10.4103/2230-973X.176490

66. Ye G, Wang S, Heng PW, Chen L, Wang C. Development and optimization of solid dispersion containing pellets of itraconazole prepared by high shear pelletization. International journal of pharmaceutics. 2007 Jun 7; 337(1-2):80-7. https://doi.org/10.1016/j.ijpharm.2006.12.028

67. Koh PT, Chuah JN, Talekar M, Gorajana A, Garg S. Formulation development and dissolution rate enhancement of efavirenz by solid dispersion systems. Indian journal of pharmaceutical sciences. 2013 May; 75(3):291. https://doi.org/10.4103/0250474X.117434

68. Prasad R, Radhakrishnan P, Singh SK, Verma PR. FurosemideSoluplus ${ }^{\circledR}$ Solid Dispersion: Development and Characterization. Recent patents on drug delivery \& formulation. 2017 Dec 1; 11(3):211-20. https://doi.org/10.2174/1872211311666171129120020

69. Annepogu H, Hindustan Abdul AH, Nayakanti D. Determining the best poloxamer carrier for thiocolchicoside solid dispersions. Turkish Journal of Pharmaceutical Sciences. 2020 Aug 17(4):372. https://doi.org/10.4274/tjps.galenos.2019.78800

70. Hussain A, Farrukh M, Abbas N, Irfan M, Arshad MS, Bukhari NI. Effect of low melting hydrophilic carriers on the solubility and dissolution rate of Piroxicam using solid dispersion technique. Pakistan journal of pharmaceutical sciences. 2019 Sep 1; 32(5 (Supplementary)):2257-60.

71. Alam MA, Al-Jenoobi FI, Al-Mohizea AM, Ali R. Effervescence assisted fusion technique to enhance the solubility of drugs. AAPS PharmSciTech. 2015 Dec; 16(6):1487-94. https://doi.org/10.1208/s12249-015-0381-2

72. Han F, Zhang W, Wang Y, Xi Z, Chen L, Li S, Xu L. Applying supercritical fluid technology to prepare ibuprofen solid dispersions with improved oral bioavailability. Pharmaceutics. 2019 Feb; 11(2):67. https://doi.org/10.3390/pharmaceutics11020067

73. Altaani B, Obaidat R, Malkawi W. Enhancement of dissolution of atorvastatin through preparation of polymeric solid dispersions using supercritical fluid technology. Research in Pharmaceutical Sciences. 2020 Apr; 15(2):123. https://doi.org/10.4103/17355362.283812 
74. Djuris J, Milovanovic S, Medarevic D, Dobricic V, Dapčević A, Ibric S. Selection of the suitable polymer for supercritical fluid assisted preparation of carvedilol solid dispersions. International journal of pharmaceutics. 2019 Jan 10; 554:190200. https://doi.org/10.1016/j.ijpharm.2018.11.015

75. Obaidat RM, Tashtoush BM, Awad AA, Al Bustami RT. Using supercritical fluid technology (SFT) in preparation of tacrolimus solid dispersions. AAPS PharmSciTech. 2017 Feb; 18(2):481-93. https://doi.org/10.1208/s12249-016-0492-4

76. Yang R, Li Y, Li J, Liu C, Du P, Zhang T. Application of scCO2 technology for preparing CoQ10 solid dispersion and SFCMS/MS for analyzing in vivo bioavailability. Drug development and industrial pharmacy. 2018 Feb 1; 44(2):289-95. https://doi.org/10.1080/03639045.2017.1391833

77. Jun SW, Kim MS, Jo GH, Lee S, Woo JS, Park JS, Hwang SJ. Cefuroxime axetil solid dispersions prepared using solution enhanced dispersion by supercritical fluids. Journal of pharmacy and pharmacology. 2005 Dec; 57(12):1529-37. https://doi.org/10.1211/jpp.57.12.0003

78. Guan J, Han J, Zhang D, Chu C, Liu H, Sun J, He Z, Zhang T. Increased dissolution rate and oral bioavailability of hydrophobic drug glyburide tablets produced using supercritical CO2 silica dispersion technology. European Journal of Pharmaceutics and Biopharmaceutics. 2014 Apr 1; 86(3):37682. https://doi.org/10.1016/j.ejpb.2013.10.008

79. Cai C, Liu M, Li Y, Guo B, Chang H, Zhang X, Yang X, Zhang T. A silica-supported solid dispersion of bifendate using supercritical carbon dioxide method with enhanced dissolution rate and oral bioavailability. Drug development and industrial pharmacy. 2016 Mar 3; 42(3):412-7. https://doi.org/10.3109/03639045.2015.1071833

80. Liu H, Zhou LL, Wei LL, Hong-Guo, Nie SF, Yang XG, Tang R, Pan WS. Preparation of budesonide-poly (ethylene oxide) solid dispersions using supercritical fluid technology. Drug development and industrial pharmacy. 2007 Jan 1;33(9):959-66. https://doi.org/10.1080/03639040601134181

81. Obaidat RM, Khanfar M, Ghanma R. A comparative solubility enhancement study of cefixime trihydrate using different dispersion techniques. AAPS PharmSciTech. 2019 Jul; 20(5):1-3. https://doi.org/10.1208/s12249-019-1395-y

82. De Zordi N, Moneghini M, Kikic I, Grassi M, Castillo AE, Solinas D, Bolger MB. Applications of supercritical fluids to enhance the dissolution behaviors of Furosemide by generation of microparticles and solid dispersions. European journal of pharmaceutics and biopharmaceutics. 2012 May 1; 81(1):13141. https://doi.org/10.1016/j.ejpb.2012.01.002

83. Wang Y, Fang Y, Zhou F, Liang Q, Deng Y. The amorphous quercetin/hydroxypropylmethylcellulose acetate succinate solid dispersions prepared by co-precipitation method to enhance quercetin dissolution. Journal of Pharmaceutical Sciences. 2021 May 15. https://doi.org/10.1016/j.xphs.2021.05.004

84. Mann AK, Schenck L, Koynov A, Rumondor AC, Jin X, Marota M, Dalton C. Producing amorphous solid dispersions via coprecipitation and spray drying: impact to physicochemical and biopharmaceutical properties. Journal of pharmaceutical sciences. 2018 Jan 1; 107(1):183-91. https://doi.org/10.1016/j.xphs.2017.07.001

85. Dong Z, Chatterji A, Sandhu H, Choi DS, Chokshi H, Shah N. Evaluation of solid-state properties of solid dispersions prepared by hot-melt extrusion and solvent co-precipitation. International journal of pharmaceutics. 2008 May 1; 355(12):141-9. https://doi.org/10.1016/j.ijpharm.2007.12.017

86. Bhujbal SV, Pathak V, Zemlyanov DY, Taylor LS, Zhou QT. Physical stability and dissolution of lumefantrine amorphous solid dispersions produced by spray anti-solvent precipitation. Journal of pharmaceutical sciences. 2021 Jun 1; 110(6):2423-31. https://doi.org/10.1016/j.xphs.2020.12.033

87. Sonali D, Tejal S, Vaishali T, Tejal G. Silymarin-solid dispersions: characterization and influence of preparation methods on dissolution. Acta Pharmaceutica. 2010 Dec 1; 60(4):427. https://doi.org/10.2478/v10007-010-0038-3

88. Hou HH, Rajesh A, Pandya KM, Lubach JW, Muliadi A, Yost E, Jia W, Nagapudi K. Impact of method of preparation of amorphous solid dispersions on mechanical properties: comparison of coprecipitation and spray drying. Journal of pharmaceutical sciences. 2019 Feb 1; 108(2):870-9. https://doi.org/10.1016/j.xphs.2018.09.008

89. Khatri Z, Kim IS, Kim SH. Functional nanofibers: production and applications.

90. Yu DG, Li JJ, Williams GR, Zhao M. Electrospun amorphous solid dispersions of poorly water-soluble drugs: A review. Journal of Controlled Release. 2018 Dec 28; 292:91-110. https://doi.org/10.1016/j.jconrel.2018.08.016

91. Iqbal B, Ali A, Ali J, Baboota S, Gupta S, Dang S, Muhammad S, K Sahni J. Recent advances and patents in solid dispersion technology. Recent patents on drug delivery \& formulation. 2011 Sep 1; 5(3):244-64. https://doi.org/10.2174/187221111797200551

92. Ziaee A, O'Dea S, Howard-Hildige A, Padrela L, Potter C, Iqbal J, Albadarin AB, Walker G, O'Reilly EJ. Amorphous solid dispersion of ibuprofen: A comparative study on the effect of solutionbased techniques. International journal of pharmaceutics. 2019 Dec 15; 572:118816. https://doi.org/10.1016/j.ijpharm.2019.118816

93. Nagy ZK, Balogh A, Démuth B, Pataki H, Vigh T, Szabó B, Molnár K, Schmidt BT, Horák P, Marosi G, Verreck G. High speed electrospinning for scaled-up production of amorphous solid dispersion of itraconazole. International journal of pharmaceutics. 2015 Mar 1; 480(1-2):137-42. https://doi.org/10.1016/j.ijpharm.2015.01.025

94. Szabó E, Záhonyi P, Brecska D, Galata DL, Mészáros LA, Madarász L, Csorba K, Vass P, Hirsch E, Szafraniec-Szczęsny J, Csontos I. Comparison of Amorphous Solid Dispersions of Spironolactone Prepared by Spray Drying and Electrospinning: The Influence of the Preparation Method on the Dissolution Properties. Molecular Pharmaceutics. 2020 Dec 10; 18(1):317-27. https://doi.org/10.1021/acs.molpharmaceut.0c00965

95. Démuth B, Farkas A, Balogh A, Bartosiewicz K, Kállai-Szabó B, Bertels J, Vigh T, Mensch J, Verreck G, Van Assche I, Marosi G. Lubricant-induced crystallization of itraconazole from tablets made of electrospun amorphous solid dispersion. Journal of pharmaceutical sciences. 2016 Sep 1; 105(9):2982-8. https://doi.org/10.1016/j.xphs.2016.04.032

96. Modica de Mohac L, Keating AV, de Fátima Pina M, RaimiAbraham BT. Engineering of nanofibrous amorphous and crystalline solid dispersions for oral drug delivery. Pharmaceutics. 2019 Jan; 11(1):7. https://doi.org/10.3390/pharmaceutics11010007

97. Yu DG, Li JJ, Williams GR, Zhao M. Electrospun amorphous solid dispersions of poorly water-soluble drugs: A review. Journal of Controlled Release. 2018 Dec 28; 292:91-110. https://doi.org/10.1016/j.jconrel.2018.08.016

98. Casian T, Borbás E, Ilyés K, Démuth B, Farkas A, Rapi Z, Bogdan C, Iurian S, Toma V, Știufiuc R, Farkas B. Electrospun amorphous solid dispersions of meloxicam: Influence of polymer type and downstream processing to orodispersible dosage forms. International journal of pharmaceutics. 2019 0ct 5; 569:118593. https://doi.org/10.1016/j.ijpharm.2019.118593 